\section{O cotidiano do cuidado infantil em comunidades rurais do Estado da Bahia: uma abordagem qualitativa}

\section{Day-to-day child care in rural communities in the State of Bahia, Brazil: a qualitative approach}

Micheli Dantas Soares 1

Thereza Cristina Bahia Coelho 2

1 Centro de Ciências da Saúde. Universidade Federal do Recôncavo da Bahia. Rua do Cajueiro, s.n. Santo Antônio de Jesus. BA, Brasil. CEP: 44.574-490

E-mail: soares_md@yahoo.com.br

2 Departamento de Saúde. Universidade Estadual de Feira de Santana. Feira de Santana, BA, Brasil

\begin{abstract}
Objectives: understand the experience and the meaning of child care for those who practice it in the home.

Methods: a phenomenological theoretical approach was used to analyze and interpret extracts from semi-structured interviews conducted with those responsible for the child care in 10 households in the city of Caldas de Cipó, in the State of Bahia, Brazil.

Results: of the various aspects of the child care, nutrition was the one of greatest concern to interviewees, given the conditions of poverty in which they live. The provision of food supplies is a key element of nutrition. The nature of the caring experience was connected not only with the personal history of the individual but also with their relationship to the dayto-day world of a particular time and space.

Conclusions: given the existential meaning of care, the results of this study suggest a shift of focus in policy and actions directed at the health education of female caregivers.
\end{abstract}

Key words Child care, Caregivers, Health education

\section{Resumo}

Objetivos: compreender as experiências e sentidos do cuidado infantil, por quem o agencia no espaço doméstico.

Métodos: foi utilizado o aporte teórico oriundo da fenomenologia na análise e interpretação dos textos extraídos das entrevistas semi-estruturadas, realizadas com as responsáveis por prover o cuidado no espaço das 10 unidades domésticas escolhidas, na sua totalidade composta por mulheres. A investigação sobre cuidado infantil foi realizada no municipio de Caldas de Cipó, Bahia, Brasil.

Resultados: entre as várias dimensões do cuidado infantil, o alimentar constitui-se como uma das principais preocupações das agentes, sobretudo pela condição de pobreza em que as mesmas vivem. A garantia da comida conforma o elemento chave do cuidado alimentar. As experiências do cuidar, informadas pelas agentes, dialogam não só com as suas situações biográficas, como também com relações que guardam com o mundo cotidiano, num tempo e espaço particularizados.

Conclusões: pelo sentido existencial que caracteriza o cuidado, os resultados deste estudo sugerem um novo enfoque na condução das políticas e ações de educação em saúde para as mulheres cuidadoras.

Palavras-chave Cuidado infantil, Cuidadores, Educação em saúde 


\section{Introdução}

Estudos de âmbito nacional realizados ao longo das últimas décadas informam sobre a magnitude do problema da desnutrição infantil e sua evolução temporal, indicando um declínio na sua prevalência. ${ }^{1,2}$ Entre os fatores associados a tais avanços estão: ampliação do acesso aos serviços públicos; aumento das coberturas vacinais e de serviços de saneamento básico; ampliação da rede básica de assistência e das práticas de atenção primária à saúde; aumento da proporção de alfabetizados (em especial as mulheres); ampliação dos meios de comunicação de massa.1,2, além das intervenções de suplementação alimentar e dos programas de transferência de renda. $3-5$

Outros estudos têm sido empreendidos na tentativa de identificar fatores que possam interferir no estado nutricional. Entre estes, tem emergido o cuidado oferecido à criança, sendo que o enfoque destas pesquisas gira em torno da caracterização dos fatores que determinam a capacidade de oferecer cuidado à criança entre os responsáveis pelo seu agenciamento no espaço doméstico, geralmente as mães, 6-8 fazendo referência a características maternas, tais como: idade da mãe ao nascimento da criança, estado conjugal e mudanças no mesmo, intervalo interpartal e número de irmãos, ou ainda trabalho fora de casa, situações de stress vivenciadas na família, estrutura familiar adversa, entre outros. 8

A escolaridade materna ganha relevância no protocolo dessas investigações, propiciando ou não a adequação de uma série de práticas de saúde, assim como a forma como a mulher dedica seu tempo à criança, que poderia ser influenciada pelo seu grau de instrução. 7

Essas condições colocam em relevo a importância da figura materna na determinação do estado nutricional da criança e sinalizam importantes aspectos do cotidiano. O tempo gasto no cuidado da criança parece ser um desses aspectos que, sob a influência dos desajustes familiares, da escolaridade materna, do trabalho fora de casa, representa uma espécie de termômetro do cuidado que se oferece à criança. Ou seja, tanto o dispêndio de tempo, ${ }^{9}$ como a existência de condições favoráveis para otimizá-lo qualificariam o cuidado dispensado à criança, sobretudo pelas mães.

Todos os fatores citados anteriormente, com ênfase no tempo destinado à criança e características biológicas, sociais e emocionais das mães ou do cuidador, foram reconhecidos pela World Health Organization (WHO) 10 como elementos que compõem o modelo conceitual de determinação do estado nutricional infantil, devendo ser considerados para o sucesso das intervenções na área de saúde e nutrição para esse público.

A valorização do cuidado na compreensão da saúde e nutrição evoca uma dimensão importante a ser considerada - o cotidiano. É nessa dimensão que as causas estruturais de determinação são corporificadas e assumem um conteúdo manifesto. É no cotidiano, "espaço e tempo das experiências", marcado por uma profusão de saberes, de valores sociais e culturais, que os responsáveis pelo agenciamento do cuidado irão conduzir as suas práticas de cuidar.

É no cotidiano, fruto de subjetivações, que o cuidado infantil também precisa ser estudado. Por outro lado, as discussões em torno da integralidade da atenção à saúde no âmbito do Sistema Único de Saúde (SUS) põem em relevo a categoria cuidado, que se expressa e se espalha no cotidiano dos contextos de atenção à saúde e da vida dos indivíduos. O sentido da integralidade passa a englobar a noção de cuidado como uma importante prática a ser assumida no âmbito da atenção à saúde. Na perspectiva de Ayres, 11 o ato de cuidar, em saúde, se insere no cotidiano da vida e deve valorizar a relação dos indivíduos com o mundo, com o seu contexto, protagonizando-os.

Desta forma, o cuidar em saúde solicita uma resignificação dos serviços e das práticas de saúde, articuladas com outros espaços de cuidado que constituem o mundo da vida cotidiana e, sobretudo, com os sujeitos, o que o torna uma "categoria de existência do cotidiano", tal como descrito por Santos, em 1999, citado por Pinheiro e Matos (2005: 32). 12 Para esse autor, o cuidado configura-se "como lócus de signos de integralidade", ocorrendo em diferentes espaços e tempos, reunindo um conjunto de ações e objetos, de manipulação de técnicas e administração de tempo que se articulam no mundo vivido.

Assim, considerando-se sua procedência, o cuidado deve ser também compreendido a partir da subjetividade que o inspira. Deste modo, faz-se necessário traduzir aqueles fatores que informam sobre a capacidade de cuidar dos agenciadores, dando escuta aos sentidos que eles próprios dão às suas práticas no cotidiano.

Compreender os sentidos das experiências significa dar visibilidade e escuta a sujeitos que são constantemente demandados pela esfera pública de formulação de políticas para o grupo infantil, e pelos executores das mesmas. Contudo, estabelecer responsabilidades a sujeitos sem aproximar-se do modo como vivem, como sentem, como atribuem 
sentidos e significados às suas experiências e ações, pode implicar em deixar enevoadas as condições concretas de operacionalização dessas políticas.

Investigações que possam abranger as várias dimensões do cuidado infantil se fazem oportunas, já que os sentidos do cuidar e o reconhecimento dos valores sociais e culturais que estão no seu entorno são necessários para subsidiar ações e políticas de educação em saúde, pautadas na realidade dos que participam dessas ações, possibilitando um diálogo real e respeitador dos universos que os tomam.

Partindo do pressuposto de que deve existir uma determinada maneira de cuidar, informada pelas condições de vida de cada pessoa, de cada grupo, de cada contexto histórico, este trabalho teve por objetivo compreender as características, o sentido e os valores sociais e culturais que direcionam essa prática no cotidiano.

\section{Métodos}

Tendo em vista a natureza do objeto elegeu-se a abordagem qualitativa para o desenvolvimento da investigação, entendendo que o objetivo que balizou o estudo demanda um arsenal metodológico de natureza compreensiva e interpretativa, capaz de se aproximar do universo de sentidos e práticas daqueles que agenciavam o cuidado infantil no âmbito doméstico, buscando situá-los no seu contexto e nas suas relações. 13

No campo da abordagem qualitativa, adotou-se a perspectiva fenomenológica, a qual representa uma teoria do conhecimento que, ao dirigir-se à experiência vivida pelos sujeitos sociais, contextualizados em seu mundo, busca interpretar o significado das suas ações e das suas expressões, do modo como as tornam conscientes, conforme explicita Critelli, em 1996, citado por Macedo (2000: 47).14

Em Heidegger, 15 o cuidado é compreendido como a constituição do ser que se dá no tempo, em todo movimento de existir e acontecer no mundo que o circunda. Pode-se dizer que a vida é um projeto, e a partir de se estar lançado em uma pré-compreensão de mundo, pode-se projetar para algumas possibilidades e não para outras, sem, contudo, ultrapassar as fronteiras do mundo em que se está inserido lançado. Esse exercício ocorre por suas relações com dois planos: o da existência, isto quer dizer "com outro ser", e o dos entes, "as coisas do mundo". É nesse "ser-no-mundo-com-outros" que se manifesta o sentido do ser como modo de lidar com o que vem ao seu encontro. As relações com os entes - as coisas do mundo - são denominadas de "ocupação"; as relações com os entes - também dotados do seu modo de ser - de "preocupação". Nesse sentido, o cuidado com a criança, por constituir-se numa relação com outro ser, é "preocupação".

O universo empírico do estudo foi o município de Caldas de Cipó - interior do Estado da Bahia, Brasil. O município dista $242 \mathrm{~km}$ de Salvador. Localiza-se no sertão baiano, região do agreste e, apesar da localização, é conhecido por possuir águas minerais termais. Foram selecionadas áreas pauperizadas que têm sido prioritárias quando da formulação e implementação de políticas sociais.

Este trabalho foi realizado paralelamente a um estudo mais extenso intitulado "Avaliação do Impacto do Programa Bolsa Alimentação em três municípios do Estado da Bahia: Calda de Cipó, Piraí do Norte e Irará", financiado pelo Ministério da Saúde e executado pelo Centro Colaborador Nordeste II.

Um dos autores integrou o grupo de pesquisadores que esteve presente na comunidade para desenvolver o estudo sobre o impacto do Programa Bolsa Alimentação, tendo realizado entrevistas sobre o cuidado infantil. Com o intuito de tornar as entrevistas mais fluidas e espontâneas, uma vez que as mesmas foram desenvolvidas seguindo um roteiro aberto, elas foram realizadas antes do protocolo da investigação sobre o Programa Bolsa Alimentação, o qual foi aplicado, em momento posterior, pela equipe responsável pela investigação. Em função do protocolo sobre o Bolsa Alimentação ser um formulário estruturado e com perguntas fechadas, considerou-se que os sujeitos da pesquisa poderiam não desenvolver um diálogo livre após a aplicação desse protocolo.

A escolha das unidades domésticas para integrar o presente estudo obedeceu ao critério de as mesmas terem ao menos uma criança menor de cinco anos, pois nessa faixa etária, alvo especial das políticas infantis, as práticas de cuidado são diferentes das fornecidas para crianças maiores. Os informantes foram aqueles que se consideravam "responsáveis" pela criança na unidade doméstica - os agentes do cuidado.

Foram realizadas entrevistas com dez informantes, com duração média de duas horas cada, norteadas inicialmente pelo relato do dia-a-dia, ou seja, o que se faz no cotidiano. A partir de então, quando os agentes referissem o cuidado, direcionavam-se questões mais específicas sobre o cuidado infantil. Quatro delas foram feitas em dois momentos distintos para esclarecer algumas narrativas e aprofundar a temática do cuidado infantil. Todas as entrevistas foram conduzidas respeitando- 
se o momento em que o cuidado era referido pelas agentes, além de contemplar questões sobre a biografia das informantes.

A técnica utilizada para obtenção das informações foi entrevistas semi-estruturadas (oral gravadas). Todas realizadas no próprio domicílio, no ambiente em que as mesmas informavam se sentir mais a vontade para "conversar".

O principal critério definidor do número de entrevistas desenvolvidas foi a "saturação" dos dados. Ou seja, quando se observou a obtenção de um volume satisfatório de informações e uma tendência à repetição das mesmas. A análise buscou identificar, nos enunciados, os núcleos de sentido que revelassem as dimensões e os sentidos do cuidado infantil atribuídos pelos seus responsáveis em relação ao contexto de produção das narrativas. 13

$\mathrm{O}$ estudo foi aprovado pelo Comitê de Ética em Pesquisa da Universidade Federal da Bahia.

\section{Resultados e Discussão}

Os informantes deste estudo foram, na sua totalidade, mulheres - mães -, que tinham como ocupação principal os afazeres domésticos e aquelas que agregavam alguma atividade laboral, provendo renda para o sustento da família. Eram mulheres com idades entre 25 e 40 anos, todas com baixa escolaridade - apenas duas tinham completado o ensino médio, as demais encerraram os estudos no ensino fundamental. Das dez informantes entrevistadas, sete delas conviviam com seus companheiros, os quais também tinham baixa escolaridade. Nenhum dos companheiros tinha um trabalho regular e com carteira assinada.

Todas as informantes tinham pelo menos uma criança menor de cinco anos de idade e uma média de três filhos. Os domicílios tinham cobertura de luz elétrica; no entanto, o abastecimento de água pela rede pública estava presente em apenas seis domicílios. De um modo geral, as informantes relataram dificuldade de acesso aos serviços de saúde e satisfatório acesso ao sistema de ensino. Nenhuma entrevistada relatou caso de alcoolismo na família.

\section{Mãe é mãe}

Para as agentes que conviviam com seus companheiros, o papel do cuidado infantil e doméstico encontrava-se reforçado, dado que os seus companheiros se responsabilizavam pelo provimento financeiro da família. Todavia, para aquelas agentes que não coabitavam com parceiros, a preocupação em sustentar a casa caminhava junto com a de cuidar da criança. Nessa situação, as mesmas relatavam a grande dificuldade em encontrar outra pessoa para agenciar o cuidado da criança, que habitualmente ficava com as avós ou irmãos mais velhos, também crianças, normalmente meninas.

Nesse sentido, o cuidado infantil foi revelado apresentando um sentido de responsabilidade inseparável da condição feminina. Para estas informantes, a responsabilidade de cuidar constitui-se em um atributo, por que não dizer, visceral, um "dom" que corresponde a toda mulher:

[...] é como uma coisa assim, olhe, é uma responsabili-

dade que toda mulher já nasce para ter ela. Já sabe como.

Nesse enunciado é possível reconhecer que a percepção dessa responsabilidade implica no reconhecimento de um conjunto de saberes que orientam a prática do cuidar, o qual se encontra também dentro de um domínio "inerente" à natureza feminina, na perspectiva dessas mulheres. Trata-se, portanto, de atributos e saberes "natos". Por decorrência desta relação, as agentes têm dificuldade de partilhar essa responsabilidade com outras pessoas, entendendo que as mesmas não saberiam cuidar como as próprias fazem:

\footnotetext{
[...]. se eu deixar eles com o pai, quem vai cuidar deles? Vai chegar a hora de dar banho não tem quem dê banho neles. Eles vão ficar aí soltos, subindo e descendo rua descalço, sem pentear cabelo, sem tomar banho, sem comer na hora certa. Quem vai cuidar? Ninguém vai cuidar.
}

$\mathrm{Na}$ fala de uma das informantes, está muito claro que a percepção dessa responsabilidade feminina de cuidar dos filhos sustenta-se nos papéis e posições diferenciadas que homens e mulheres ocupam no contexto de organização familiar.

Considerando o agenciamento do cuidado no âmbito doméstico, remetemos à discussão que Tronto 16 realiza sobre o tema. Para o autor, o ato de cuidar representa a necessidade de algum objeto ser cuidado e, portanto, evoca uma dimensão relacional intrínseca. $\mathrm{O}$ autor distingue duas possibilidades de cuidado: o "cuidado com" e o "cuidar de", a depender do objeto a que é direcionado o cuidado. Assim, o "cuidar com" refere-se a coisas mais abstratas, significando preocupações de modo mais genérico. É uma ocupação no mundo. Já o "cuidar de" implica em um objeto específico, com necessidades particulares e concretas. O cuidar da saúde e da alimentação das crianças constitui um tipo de 
cuidado circunscrito.

Historicamente, entre as atividades habituais conferidas às mulheres no âmbito domiciliar, estão: a administração da preparação e do consumo de alimentos, socialização e cuidado dos filhos, limpeza e cuidado dos enfermos. ${ }^{17}$ Dessa forma, os significantes mais comuns legados às mulheres são o de "mãe", e, em alguma medida, de "curandeira", 18 que se apóiam exatamente nessa função social de reprodução e cura.

No contexto estudado, percebe-se que os termos que dão acesso ao universo significativo das entrevistadas revelam o quão sedimentado estão os papéis sociais de gênero constituídos histórica e culturalmente. As agentes têm na responsabilidade o sentido no qual o cuidado movimenta as ações e práticas no cotidiano:

[...]. é uma coisa como, por exemplo, alguém te deixa

alguma coisa com você e diz: 'Olhe, isso aqui é responsa-

bilidade sua, quando eu voltar eu quero do mesmo jeito que eu te dei'. Parecido isso! A gente sente que ali é um objeto seu, só seu, e que só você sabe cuidar. Se você deixar para outra pessoa não sabe.

As mudanças que ocorrem nos papéis desenvolvidos por homens e mulheres na sociedade sofrem condicionamentos de uma sorte de fatores. Para Sarti, 19 as populações de baixa renda são as que mantêm com mais solidez a tradição como referência fundamental de existência, já que não dispõem de recursos simbólicos para projetos pessoais alheios ao seu universo cultural e material. Desta forma, as relações de gênero tomam maior evidência no mundo cotidiano do grupo estudado, no qual parece estar mais cristalizado o papel reprodutivo da mulher no tecido social. Neste aspecto, a bagagem de conhecimentos disponíveis constitui-se em uma "construção social naturalizada". ${ }^{20}$ Logo, são elas, as mulheres, sobretudo mães, que encontram no legado cultural o cuidado com a criança. São projetos reconhecidos numa co-existência coletiva.

\section{O filho}

O filho, por sua vez, o tal "objeto" - objeto só dela, responsabilidade dela, cuidado dela, representa, para as agentes, um conflito. Por um lado, motivadas por uma carência material que impossibilita a realização do cuidado conforme suas expectativas, o filho expõe de modo mais contundente as ausências e faltas que sempre marcaram a história de vida delas. Por outro lado, representa também, esse "objeto", a oportunidade de reconstrução dessa existência carente. Por intermédio do esforço, do cuidado da mãe, poderá essa extensão dela avançar para a completude, para uma existência mais plena, mais feliz e menos vazia que a própria.

Esta mesma representação do filho foi encontrada em estudo realizado por Onesti, 21 no qual a criação dos filhos pode concorrer favoravelmente para elevação da auto-estima. Este conflito é marcado pelo que se apresenta como tal e pelo que pode vir a ser, presente e futuro, mediando a ausência e a presença.

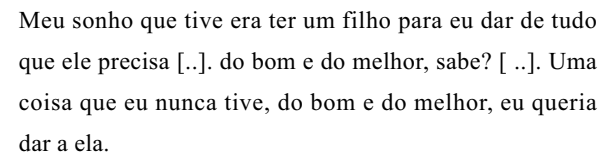

Nesse sentido, o filho representa tanto a realização de um sonho de corporização, encarnação da condição feminina, quanto o desejo de que este ser ultrapasse as carências materiais que as mesmas vivenciaram e lutam para fugir. Dessa forma, os filhos figuram, para suas agentes, como um sonho de ser e um desejo de "ter tido".

A projeção de um futuro, pelas mulheres pauperizadas, encontrava-se indissociável do futuro dos seus filhos. A superação desta condição de herança de privações só poderá ocorrer, entretanto, por meio de novas renúncias, que vão configurar a cotidianidade dessas agentes.

[...] eu não vou comprar para mim e deixar elas sem roupa, eu prefiro comprar para elas. Se eu preciso de uma sandália, se ela não tiver, eu não compro para mim, eu tenho que comprar para elas.

\section{Os afazeres}

Quando as agentes são questionadas sobre o seu dia-a-dia, as mesmas descrevem o conjunto de atividades que são desenvolvidas, inclusive as ações direcionadas aos seus filhos. Estes enunciados são uma "expressão da vida". Trata-se de um cotidiano objetivado em rotinas que conformam o imediato que se impõe no dia-a-dia sem espaço de reflexão. As descrições sobre o "cuidado infantil" entre as atividades do cotidiano apresentam-se, inicialmente, de forma relutante, difíceis de serem retratadas, pois as ações de cuidado parecem coincidir com algo já postulado, que se encontra no senso comum, executável por todos sem distinção, como se apresentassem atributos evidentes por si mesmos, não passíveis de esclarecimento:

[...] cuidado é como todo mundo faz, todos nós já 
crescemos aprendendo a fazer, quando a gente vê já está sabendo como faz, como cuida, já tem uma coisa assim natural de fazer.

Para estas agentes, o cuidado com as crianças aprende-se naturalmente, num aprendizado empírico, implícito nas relações interpessoais dispostas no dia-a-dia. Deste modo, a filha aprende com sua mãe como cuidar da casa e das crianças menores. $\mathrm{O}$ "nós" representa um aprendizado não sistemático, mas presente durante toda a vida, não se constituindo como um saber solitário, melhor dizendo, privativo, mas, sobretudo reconhecido num universo coletivo de outros pares que compartilham desse mesmo saber nas suas histórias de vida.

As agentes apreendem, no cotidiano, os atos que conformam o cuidado e são repassados por gerações, produzidos nas experiências concretas. Amparadas na imitação, elas vão costurando com espontaneidade, mediante o encontro com o outro, e com os antepassados, as ações que o caracterizam. ${ }^{22}$

Em que pese o cuidado ter sido revelado predominantemente naturalizado, o mesmo não deixa de ser veiculado em outros distintos espaços. A escola e o posto de saúde anunciam formas de cuidar, normatizações das ações cotidianas que devem marcar as preocupações das agentes:

[...] é como todo mundo já sabe, na escola mesmo, os meninos vem dizendo que ensinou que tem que escovar o dente, tem que lavar as mãos, as verduras, não pode andar sujo, essas coisas todas. A moça do posto que vem aqui também diz a mesma coisa. Acho até engraçado, e falei para ela, já sei dessa cartilha, a gente sabe de todos os cuidados que tem que ter para a criança não adoecer e pegar as bactérias não é?

$\mathrm{Na}$ fala acima, uma das mães promove um discurso (ou contra-discurso) que revela a sua apreensão das práticas preconizadas no âmbito da saúde e da escola. A utilização irônica do significante "cartilha" denuncia uma apreensão crítica das normas biomédicas, como uma atividade pedagógica alienadora, uma vez que são estranhas às condições concretas de vida. São discursos que, em certa medida, não contextualizam os sujeitos, em contraposição a uma prática educativa que tanto apreende a objetividade da realidade como o modo como esta é subjetivada pelos sujeitos em ação. 23

Por outro lado, as demandas colocadas, ainda que de modo implícito, pelas políticas sociais e serviços de atenção infantil, reforçam o papel da mulher no ambiente doméstico, como extensão do cuidado assistencial:

[..] não deixo nunca faltar [...] nunca deixei faltar uma vacina dela. O cartão dela sempre completinho, todo completo. Nunca deixei um mês de ela passar sem tomar vacina, todo mês eu levava. Coisa assim que ela precisava, sabe?

As práticas de saúde habitualmente desenvolvidas na atenção básica para o público infantil estão caracterizadas nas respostas das informantes, que associam, evidentemente, a pesquisadora com a normatividade da área da Saúde recitando, para ela, a tal cartilha "preventiva":

Ela não cai doente para eu levar no médico. Levo ela todo mês quando eu tô [...] quando eu não tenho nada para fazer. Passa alguma vitamina para ela tomar, passa sulfato ferroso, passa remédio de verme. Porque a gente não pode levar uma criança porque a criança está doente, morrendo!

Nos distintos cenários relacionais, a naturalização e a norma caminham paralelamente, numa teia de resistências e interpenetração, onde as experiências de cuidar obedecem a prescrições que vão imprimindo uma projeção do "que fazer".

\section{A caça à comida}

A refeição traduz uma dimensão privilegiada do cuidado, tanto do ponto de vista da continuidade da oferta do alimento, quanto da qualidade da alimentação que está sendo oferecida. Interpretando as entrevistas, foi possível observar que o cuidado alimentar toma maior visibilidade que os demais, pois atende, em boa parte das vezes, a uma solicitação premente: o choro da criança. Muito possivelmente, por esse motivo, torna-se imperativo face às demais ações que conformam o cuidado.

Um outro aspecto diz respeito ao fato de que a escassez do alimento manifesta de modo mais claro a situação de pauperidade. Esta condição encontra um sentido que não se esgota no ambiente doméstico, mas é anunciado também fora desse, quando a criança apresenta o estado de desnutrição ou de baixo peso e, sendo percebido, é alvo de comentários entre os vizinhos, ainda que os mesmos vivenciem situações similares, como também em outros espaços públicos, podendo denotar não somente o reflexo de uma condição de carência e privação, mas também a negligência do cuidado:

[...] assim a preocupação com o cuidado da comida é o que eu mais me importo porque a criança vai se dismilinguindo, e aí todo mundo fica vendo, fica notando e fica sabendo de tudo que tá acontecendo e ainda vai dizer "ói aí ói que mãe mais descuidada é essa", é como assim diz 
saco vazio não fica em pé, a gente tem que andar pra encher esse saco, não é?

O cuidado alimentar, por se tratar de ação inscrita no cotidiano, constante e problemático em face da escassez, aparece expresso em ações sinalizadoras para o qual ele é o fundamento, a motivação, como o tecer rede para ter o que dar na quarta-feira (dia da feira local). A prioridade na compra para o abastecimento intradomiciliar de gêneros alimentícios relaciona-se diretamente com as economias que podem ser efetuadas de modo a garantir o alimento, sobretudo para a criança.

Desta forma, as preferências alimentares ficam, em alguma medida, marginalizadas neste contexto. Quando existe um recurso maior a ser utilizado para adquirir alimentos, há uma mobilização para se comprar os que são considerados importantes para a saúde da criança. Entretanto, face ao pouco dinheiro para esses, opta-se por aqueles que podem ser partilhados por todos:

[...] aí tem que comprar [...] chega quarta eu compro maçã para eles. Compro maçã, compro aquelas frutas. Aí então eu tinha que ver: não tinha para comprar tudo, eu tinha que ver: ou comprava o feijão e arroz ou então ia comprar fruta. Então eu optava pelo feijão e o arroz que ficava para os quatro!

As situações de insegurança alimentar vivenciadas encontram abrigo nas demais casas da comunidade. Convivendo com situações de privações, os pares reconhecem no outro a sua própria condição. Nesse sentido, o cuidado alimentar é também intermediado pelos vizinhos.

Porém, não só as preocupações em ter o alimento para ser oferecido revelam o cuidado. Outras dimensões tomam forma neste cenário. Por exemplo, oferecer a comida adequada que deve ser compatível com a idade da criança, não provocando adoecimento:

[...] acho assim, que tem que dar o leite deles, né? Dar assim uma comidinha que não seja pesada para não ficar doente, um leitinho. Não dou comida muito pesada para não passar mal do estômago, e adoecer, e ficar pior para comprar remédio.

Em muitos enunciados foi possível identificar que, frente às preocupações com a inacessibilidade do alimento, as demais dimensões do cuidado vão se distanciando. Assim, para além do conteúdo das normas sobre o cuidado, as situações reais vão se impondo no dia-a-dia, redefinindo práticas, com conseqüências que contrariam o desejo daquela que agencia o cuidado:

[...] e às vezes você não consegue realizar, nem como pessoa tua você não consegue, a gente tem outras preocupação, o menino está fazendo de tudo, mas sua cabeça está pensando é em outra coisa, no combustível de dar para eles [...] a gente nem dá mais atenção para ele.

\section{A hora certa}

Assim, as entrevistas anunciam o que é feito, o que há de possibilidade dentro das limitações impostas pela realidade concreta. Nesta dimensão, está sempre revelado o que há de mais gritante, clamando pela imediatez, que é o alimento, dado na hora certa, posto à mesa ou no chão, mas presente.

O cuidado em oferecer para criança o alimento na hora certa apresenta um sentido temporal importante no cotidiano, uma vez que é permeado por uma condição de vida que ainda não é reconhecida pela criança. Essa condição, de acesso ao alimento, se constitui em fonte de inesgotável apreensão. A criança não tem o "costume" de passar por situações que caracterizam as dificuldades impostas pelas condições materiais de vida, sobretudo aquelas que tangenciam a ausência da comida.

Preocupações dessa natureza coincidem com os resultados de um estudo desenvolvido em bairro popular de Salvador, no qual as famílias também valorizavam a hora certa da alimentação, apoiandose em uma rede de solidariedade e reciprocidade para assegurar a alimentação da criança e, sobretudo, a prioridade que o cuidado alimentar apresentava face as demais dimensões do cuidado infantil.24

Nesse sentido, o cuidado alimentar, em especial o horário das refeições, torna-se urgente no repertório de ações que caracterizam o cuidado:

[...] a gente tem assim uma preocupação que é de dar a comida na hora certinha para eles, na hora que a barriga ronca, a gente tem que ter para dar para eles, porque a vida é assim, é tudo uma questão de costume, os menorizinhos é pior ainda, assim não estão acostumado, abre no choro, os maiorizinhos já pode se acostumar melhor.

Entre as várias preocupações, no cálculo probabilístico que direciona o caminhar no mundo da vida cotidiana,22 a busca do alimento faz-se imperativa. Assim, ela - a busca - deve anteceder o choro da criança. $\mathrm{O}$ alimento dado na hora certa representa, na temporalidade de Heidegger, a antecipação resoluta; a agente, ao deixar-se penetrar pela projeção do que pode vir a ser, toma as suas resoluções possíveis, 
o futuro apresentando-se e informando sobre o agir, agora. 25

Mas, nessa busca do alimento, encontra-se também outro aspecto: a renúncia para si e a garantia para outro - o objeto do cuidado. Nas situações em que a iminência da privação está presente é ela - a agente - quem primeiro a experimenta. ${ }^{26} \mathrm{~A}$ preocupação com o alimento/comida a um só tempo precede e desloca a atenção das mães das demais dimensões do cuidado.

\section{A casa e a rua}

No drama do cotidiano estudado, o cuidado vai se calando face às condições do ambiente, em que a água é escassa, as ruas são de barro batido e o lixo permanece por tempo indeterminado na frente da porta. Nessa situação, a pobreza intra-domiciliar fica ressaltada, cúmplice daquele lugar, a denunciar sua condição social.

Nesse aspecto, importa destacar que o convívio permanente com condições inóspitas caracteriza o "costume" em aceitar a ocorrência daquela condição, a qual ganha um status de familiaridade. Nesse cenário, o cuidado com a higiene e a aparência sucumbe à interação com o meio que os envolve e que, em certa medida, não favorece que esse tipo de cuidado se constitua. Dessa forma, o cuidado higiênico é reinterpretado, de modo a não entrar em conflito com a realidade de sujeira manifesta.

[...] está vendo os menino aí não é, eles brincam onde pode brincar, é com a mão no barro, ali o lixo está ali, eu não posso deixar os menino trancado dentro de casa, sem brincar, tem que acostumar de ver aquilo ali, de está com isso. A gente fala "menino não mexe aí, não mexe ali", vira as costas ele está ali de novo (ela aponta para o lixo e a poça de água).

A rua sem asfalto, o lixo, a areia que invade a casa e luta contra a boa intenção do asseio. A manifestação da sujeira desmobiliza porque é constante e refratária, geradora de um impasse, um conflito destinado à superação negativa. Não é possível manter a criança imóvel, parada; Para que ela viva e se desenvolva, deve explorar esse meio, ainda que sujo, ainda que inóspito, ao preço do risco e da culpa. Ou seja, o contato com o ambiente é ressaltado pelas carências da família.

Eu não tenho condições de eu comprar as coisas para eles para eles viver dentro de casa calçado, agasalhado. É por isso que eles vivem brincando na areia.

\section{Brinca na areia aí.}

Neste mundo cotidiano, que oferece resistências, limites e possibilidades, o "acostumar" caracteriza o que é possível fazer, a prática viável, diante das condições que nele se apresentam, para as quais as agentes não têm capacidade de mudar. Ele - o acostumar - se caracteriza como a necessidade de coexistência com a realidade, de resiliência, como possibilidade re-construção e re-significação das experiências. O "acostumar" é compartilhar experiências, situar-se no seu meio com estruturas que caracterizam o mundo cotidiano. 27

\section{"Descuido"}

Foi possível identificar nesse universo que também entra em cena o juízo social pelo que pode ser considerado como "descuido". Ainda que essa mesma situação seja compartilhada pela comunidade, ela não escapa à apreciação do outro, sobretudo quando esse descuido está corporificado, manifesto no estado nutricional ou na aparência da criança.

Nos termos das entrevistadas, só a mãe pode prestar o cuidado com propriedade. Logo, o "descuido" nega, de imediato, a condição primeira: ser mãe. Descuida da criança quem não experimentou a "dor do parto"; aquela dor que traz consigo a noção de responsabilidade, inserido-a no universo imaginário, cultural, do "ser mãe":

[...] é porque elas não passaram dor para ter, porque se elas passassem dor, elas não deixavam aqueles filhos passar tudo aquilo, aquela dificuldade toda.

Não obstante as informantes tragam à tona, nas suas falas, um repertório de justificativas para relativizar o agenciamento do cuidado, encontrando acolhida nas suas precárias condições de vida, elas retornam à norma e ao discurso em momento de reflexão - de valoração - sobre o seu ato e o do outro.

O juízo, portanto, não importando a quem se enderece, às vezes a si própria, ou ao outro, é duro e rigoroso com a mãe que é:

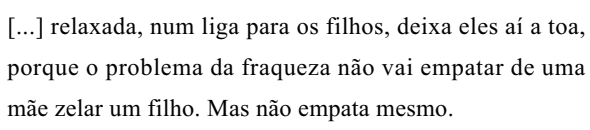

Estes pensamentos, que perpassam a reflexão sobre o ato de cuidar, são "confusos, confusos mesmos, difícil de explicar", no dizer de uma das entrevistadas. Para algumas das informantes, a situ- 
ação de pobreza não legitima o "descuido", portando-se como protagonistas da ação do cuidado, independente das circunstâncias adversas. Para outras, apesar de protagonizarem a culpa pelo "descuido", nas mesmas situações elas assumem um papel passivo, que é limitado por uma privação externa à mesma, um preocupação impotente causada pelo horizonte permanentemente escasso.

As sensações de descuido são subjetivadas de modo muito próprio e particular e devem ser analisadas considerando-se a biografia das suas agentes. O sentimento de responsabilidade que motivou o descuido pode repousar nas agentes do cuidado ou nas condições de vida em que as mesmas se encontram.

Neste sentido, os sentimentos vão desde a sensação de inutilidade ao conformismo. É possível identificar que existe um sentimento de inoperância face às adversidades materiais uma vez que, em alguma medida, elas se sentem responsáveis pela situação de pobreza, contrariando-se com o mundo de privações em que vivem. Nestas falas, reconhece-se que as agenciadoras do cuidado atribuem para si a resposta pelo alcance limitado que a realidade lhes impõe.

[...] eu sinto assim um vazio, uma dor por dentro. Sinto assim... porque queria dar isso e não posso. Você se sente uma inútil, é a palavra mais certa! Você sente [...] você sente que não é nada! Porque você não pode dar aquilo que você quer. Às vezes chegava assim o dia que eu não tinha mesmo como comprar aquilo para dar a eles[...] não tinha o dinheiro mesmo para ir comprar, aí você se sente um inseto, um traste! Você sente que é o objeto mais inútil na face da terra! Você se sente um lixo. Por dentro tudo dói! Porque eu não posso [...].

Por outro lado, há dizeres em que o não oferecer o que é necessário apresenta uma relação que ultrapassa as condições reais e passa a pertencer a um plano não mais físico, mas sim aos desígnios de um mundo sobrenatural. Diante dessa percepção, as agenciadoras inclinam-se a se conformar com aquilo que é desígnio:

[...] eu sou uma mãe que praticamente [...] sou mãe porque sou mãe mesmo, senão [...] tem mãe que dá o bom e o melhor a seu filho não é? Mas eu não posso! Faço como Deus quer.

Por fim, é no cotidiano e em correspondência com ele que as mães vão tecendo o seu cuidado, ora interpelado pelas condições concretas de vida, que negam a norma, ou permitem o que é possível de ser realizado, ora encerrando a sua intrínseca relação com a condição feminina, ora sendo repreendido, quando exposto a um juízo social, ora se revelando nos sentimentos que intermediam as práticas.

\section{Conclusões}

Esta investigação partiu do interesse de compreender como ocorre o cuidado infantil e quais os sentidos que o informam. Esta inquietação parte do pressuposto de que as ações em saúde devem necessariamente passar pela compreensão dos contextos reais do mundo cotidiano, onde as existências humanas rotineiramente desenvolvem suas formas particulares de cuidar. Desta maneira, entende-se que não é possível um diálogo de promoção de saúde e prevenção de doenças sem que o outro se pronuncie e se manifeste na sua realidade.

Assim, nas narrativas das agentes - mulheres e mães - o cuidado infantil foi se compondo, e somente por elas e através delas que o cuidado pode ser agenciado, uma vez que "mãe é mãe" e o sentido de responsabilidade conduz o agenciamento, num projeto herdado.

"O filho" - objeto do cuidado - representa o enlace do presente a expulsar um passado, ainda presente com tantas ausências, e a dialogar com um futuro que se deseja experimentado por menos carências.

Entre todos os "afazeres" que conformam o cotidiano das agentes, é preciso também conviver com toda a multiplicidade de carências, na medida que os limites entre "a casa e a rua" se misturam. Mas, entre todas as carências, é premente "a caça à comida", porque intermediada pelo choro, expressão maior da demanda, que impõe uma "hora certa" de oferecer a comida, sobretudo aos filhos mais novos.

O juízo de si e do outro por tudo o que não se pode, mas se deseja dar, pode ganhar um sentido de "descuido". A natureza dessa culpa pode estar relacionada com as condições de vida que é imposta à mãe, consigo mesma ou, ainda, com os desígnios de uma divindade.

O cuidado alimentar, nesse aspecto, merece atenção especial, não só por figurar como condição básica de sobrevivência, mas por emergir como importante dimensão do cuidado infantil. Desta forma, estudos devem ser empreendidos de modo a interpretar e compreender mais profundamente esta dimensão do cuidado infantil, que é o cuidado alimentar, explorando as ações que o caracterizam, os valores sociais e culturais inscritos nessa prática, os quais não puderam ser investigados neste estudo 
de modo mais específico.

Retornando às preocupações iniciais da pesquisa, nossos achados, colaborando com outros estudos desta natureza, desejam suscitar novos olhares que podem, antes devem, ser dirigidos ao cuidado infantil, de forma a expor o sentido que assume, o

\section{Referências}

1. Monteiro CA, organizador. Velhos e novos males da saúde no Brasil: a evolução do país e de suas doenças. São Paulo: Hucitec; 1995.

2. Iunes FR, Monteiro CA. Razões para a melhoria do estado nutricional das crianças brasileiras nas décadas de 70 e 80 . São Paulo: UNICEF; 1993.

3. Gutierrez MR, Bettiol H, Barbieri MA. Avaliação de um programa de suplementação alimentar. Rev Panam Salud Publica. 1998; 1: 32-9.

4. Castro IRR. Avaliação da operacionalização e impacto do programa de recuperação nutricional de crianças na cidade do Rio de Janeiro. Inf Epidemiol Saúde Pública. 1999; 18: 33-9.

5. Brasil. Ministério do Desenvolvimento Social e Combate à Fome. Secretaria de Avaliação e Gestão da informação. Brasília, DF; 2006. (Cadernos de Estudos Desenvolvimento Social em Debate, 4).

6. Facchini LA. Trabalho materno e nutrição infantil: situação atual e perspectivas. In: Barreto ML, Almeida Filho N, Veras RP, Barata RB, organizadores. Epidemiologia, serviços e tecnologia em saúde. Rio de Janeiro: FIOCRUZ; 1998. p. 167-86. (Série Epidemiológica, 3).

7. Cardoso MAA. Cuidado infantil e desnutrição de pré-escolares: regiões Nordeste e Sul do Brasil [tese de doutorado]. São Paulo: Faculdade de Saúde Pública da Universidade de São Paulo; 1996.

8. Carvalhães MABL, Benìcio MHDA . Capacidade materna de cuidar e desnutrição infantil. Rev Saúde Pública. 2002; 36: 188-97.

9. Castro IRR. Vigilância alimentar e nutricional: limitações e interfaces com a rede de saúde. Rio de Janeiro: Fiocruz; 1995.

10. WHO (World Health Organization). Complementary feeding of young children in developing countries: a review of current scientific knowledge. Geneva; 1998.

11. Ayres JRCM. Sujeito, intersubjetividade e práticas de saúde. Cienc Saúde Coletiva. 2001; 6: 63-72.

12. Pinheiro R, Matos RA. Construção da integralidade: cotidiano, saberes e práticas em saúde. Rio de Janeiro: CEPESC; 2005. significado que se manifesta nos seus agenciadores, as práticas e as ações que o revelam e, assim, fornecer subsídios para ações em saúde mais sensíveis e humanizantes.
13. Minayo M. O desafio do conhecimento: pesquisa qualitativa em saúde. São Paulo: Hucitec; 1992.

14. Macedo RS. A etnopesquisa crítica e multirreferencial nas ciências humanas e na educação. Salvador: Ed. UFBA; 2000

15. Heidegger M. Ser e tempo. Petrópolis: Vozes; 2002.

16. Tronto JC. Mulheres e cuidados: o que as feministas podem aprender sobre moralidade a partir disso? In: Jaggar AM, Bordo SR. Gênero, corpo, conhecimento. Rio de Janeiro: Record; 1997.

17. Colliére MF. Promover a vida: da prática das mulheres da virtude aos cuidados da enfermagem. Lisboa: Sindicato dos Enfermeiros Portugueses; 1989.

18. Helman CG. Cultura, saúde e doença. Porto Alegre: Artes Médicas; 1994

19. Sarti C. Família e individualidade: um problema moderno. In: Carvalho MCB, organizador. A família contemporânea em debate. São Paulo: Educ; 1997.

20. Bourdieu P. A dominação masculina. Rio de Janeiro: Bertrand Brasil; 1999.

21. Onesti LA. Resistência psicológica e condições de vida em mulheres de baixa renda [dissertação mestrado]. São Paulo: Instituto de Psicologia da Universidade de São Paulo; 1993.

22. Heller A. O cotidiano e a história. São Paulo: Paz e Terra; 2000.

23. Acioli S. A prática educativa como expressão do cuidado em Saúde Pública. Rev Bras Enferm. 2008; 61: 117-21.

24. Bustamante V, Trad LAB. Cuidando da saúde de crianças pequenas no contexto familiar: um estudo etnográfico com famílias de camadas populares. Ciênc Saúde Coletiva. 2007; 12: 1175-84.

25. Steiner G. As idéias de Heidegger. São Paulo: Cultrix; 1978.

26. Radimer KL, Olson CM, Campbel CC. Development of indicators to assess Hunger. J Nutr. 1990; 120: 1544-8.

27. Freitas MCS. Agonia da fome. Rio de Janeiro: Ed. UFBA; 2003.

Recebido em 28 de agosto de 2007

Versão final apresentada em 18 de setembro de 2008

Aprovado em 24 de outubro de 2008 